\title{
The Labor Theory of Value: A Masked Dialogue in the Exchange of Wound"
}

The only consistent invariant, both logically and conceptually, is the very definition of value added of the theory of value-labor, since no other invariant is consistent in the general case with this definition,

which constitutes the basis of the theory, and with the rest of its inherent propositions.

Homero Cuevas

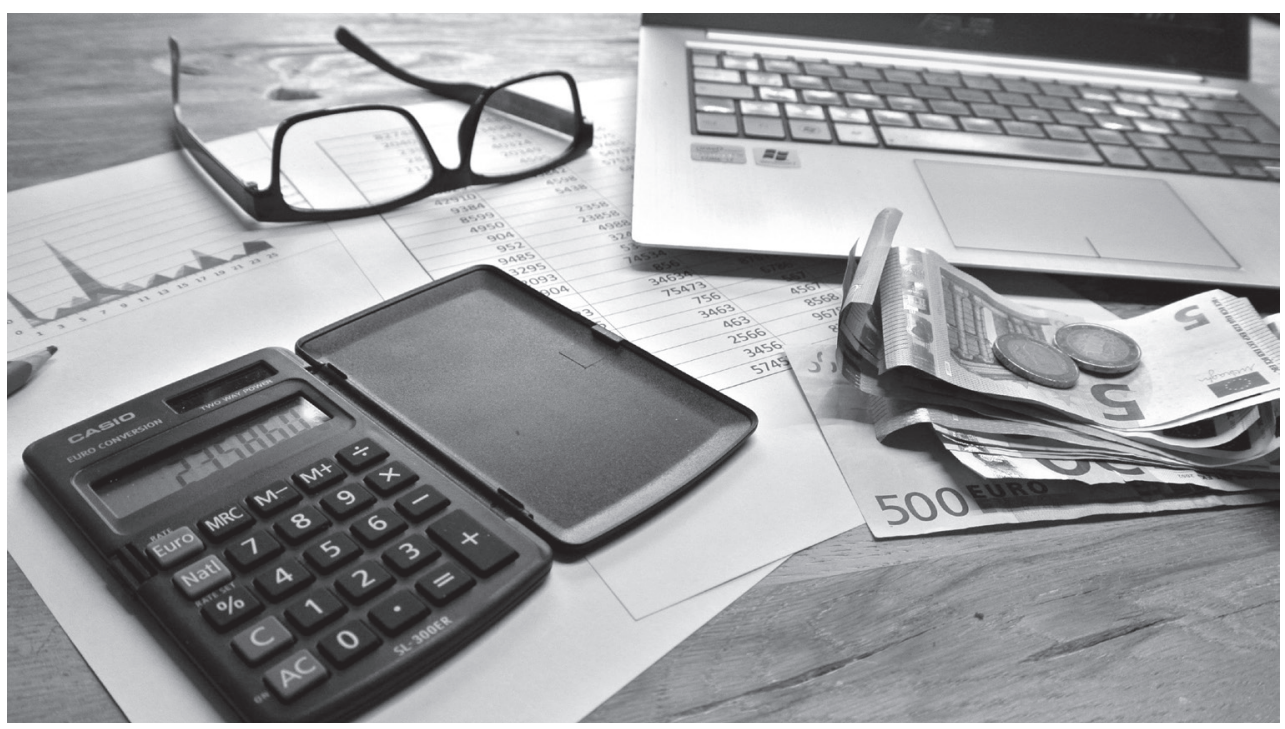

Every day we exchange the spent hours of our day. Although the outcome of this meeting is only money, most of us give our work tattooed in coins to others, almost always anonymous, in exchange for objects and services (we imagine the work of others), offered as merchandise. Centuries ago, this exchange was made between direct producers, since money was hardly used between two people who were close to value dissimilar products, although there was always the doubt about small differences in the exchange of wounds.

The complexity of the evolution of exchange led to the unraveling of valuations, especially in money and working time, to leave aside all other (non-economic) factors that intervene in the relations of production, in particular, the personal relationships between producers and consumers. As capitalism and modernity developed, economic relations and people's rationalization of life became complex, resulting in a high degree of depersonalization of social relations.

* Traducción del prof. Alexander Rodríguez. Correo electrónico: alexrodriguez6015@gmail.com 
Not only did the exchange become complex, but also the implied network of relationships, but above all, ideological evaluations (religious, solidarity, cultural, etc.) have been diluted in the private sphere. What is more, given the complexity of the production system and the distance on the genesis of value construction in products due to the fact that the information has been reduced to prices, neither individuals nor companies have the possibility of comparing neither the valuations of time worked nor the labor-value of exchange prices.

Every man is rich or poor according to the degree in which he can afford to enjoy the necessaries, conveniences, and amusements of human life. But, after the division of labor has once thoroughly taken place, it is but a very small part of these with which a man's own labor can supply him. The far greater part of them he must derive from the labor of other people, and he must be rich or poor according to the quantity of that labor which he can command, or which he can afford to purchase. The value of any commodity, therefore, to the person who possesses it, and who means not to use or consume it himself, but to exchange it for other commodities, is equal to the quantity of labor which it enables him to purchase or command. Labor, therefore, is the real measure of the exchangeable value of all commodities. (Smith, 1996, p. 64).

These circumstances of capitalist modernity overshadow the origins and possible solutions of the greatest contemporary socioeconomic injustice: economic inequality in its main dimensions such as income and property. This has fueled, from a classic like Smith, the need for an invariable measure of value, a common language for exchange:

But though labor is the real measure of the exchange value of all commodities, it is not the measure by which their value is commonly estimated. It is often difficult to ascertain the proportion between two different quantities of labor. The time spent in two different sorts of work will not always alone determine this proportion. The different degrees of hardship endured and of ingenuity exercised must likewise be taken into account. There may be more labor in an hour's hard work than in two hours of easy business; or in an hour's application to trade which it cost ten years' labor to learn than in a month's industry at an ordinary and obvious employment. But it is not easy to find an accurate measure either of hardship or ingenuity (Smith, 1996, pp. 65-66).

And the above, of course, leads to distorting and confusing the merits and valuations of workers regarding their contribution to the production processes and the way in which the distribution of the product is undertaken. Every day the face of our labor hours is more hidden in the exchange of our hands, the uncertain past of our or your ancestors, or of the theft of some, who decide on the power to buy between us. The historical, legal and economic tracking of property requires a transversal (time) and vertical (products) comparison mode. Faced with this need, Smith casts an anchor in the turbulent waters of the exchange of hours worked by individuals, in the staging of their targeted products: the market.

It is clear, therefore, that labor is the only universal and accurate measure of value, or the only standard by which we can compare the values of different 
commodities at any time and place. We cannot, of course, estimate the actual value of various commodities from one century to the next based on the amounts of silver delivered in exchange for them. Nor can we estimate it from one year to the next according to the amounts of cereal. But according to the amounts of labor we can estimate it with the greatest precision both from one century to another and from one year to the next (Smith, 1996, pp. 72-73).

Exchange measured in prices hides not only its value, it also masks surplus value. It transforms the way of relating in society, it transfers the sacrifice of time spent in exchange (it dissolves the polis), it traps us in an institutionalized complexity in which the alienation of individuals takes the form of capital: unspent hours pile up on the dry cut logs, safe, to ensure tomorrow's fire. But the hours counted are not enough for the accounting of the exchange. Unshared dreams and desires impose sacrifice from the circumstances of each route on the personal calendar. The market price then measures, beyond incorporated labor, the historical constraints of the participants' delivery from each shore. Then the justice of time in exchange multiplies their faces until we lose ourselves in their labyrinths: we are overwhelmed by the salary assessed under the history of our hands arbitrated by capital. And in this revisited path of the classics of the economy we went to Ricardo to comment on how this language of price weaves deviations from the natural price, from the hours of exchange:

When considering labor as the basis of goods, and the comparative amount of labor necessary for their production, as the rule that determines the quantities that must be delivered in exchange for each other, we should not assume that we deny accidental and temporary deviations that real or market prices of goods undergo, in relation to their primary and natural price (Ricardo, 1997, p. 67).

So, the need to find an invariant is not only pressing, but a condition to build dialogue for what is fair. The imperative of this search cannot abolish the difficulties in finding it. By definition, due to the nature of the phenomenon, only labor-value can account for a theory of value towards a just one; other evaluations will be efficient, or measure a dimension of it; but the invariant of labor is not only concerned with exchange but with the history of the language used as its currency, language which founds realities. The amount of work exchanged fixes phonemes, universal sounds. Then the problem will no longer be in the words as the merchandise clothing, but in the individual tragedy of each one to establish the merchandise borders in his being. And following Marx, labor power as a commodity is the origin and the end of the question: "The process of consumption of labor power is, at the same time, the process of production of the commodity and of surplus value" (Marx, 1954, p. 485).

The unit of measure is measured by itself. This language trap, already studied in other spheres of knowledge (Wittgenstein), makes this economic debate a structuringstructured fact (Bourdieu):

The value of labor power, like that of all other merchandise, is determined by the labor time necessary for production, including, therefore, the reproduction of this specific article. Considered as a value, labor power represents only a certain amount of average social work materialized in it. Labor power exists 


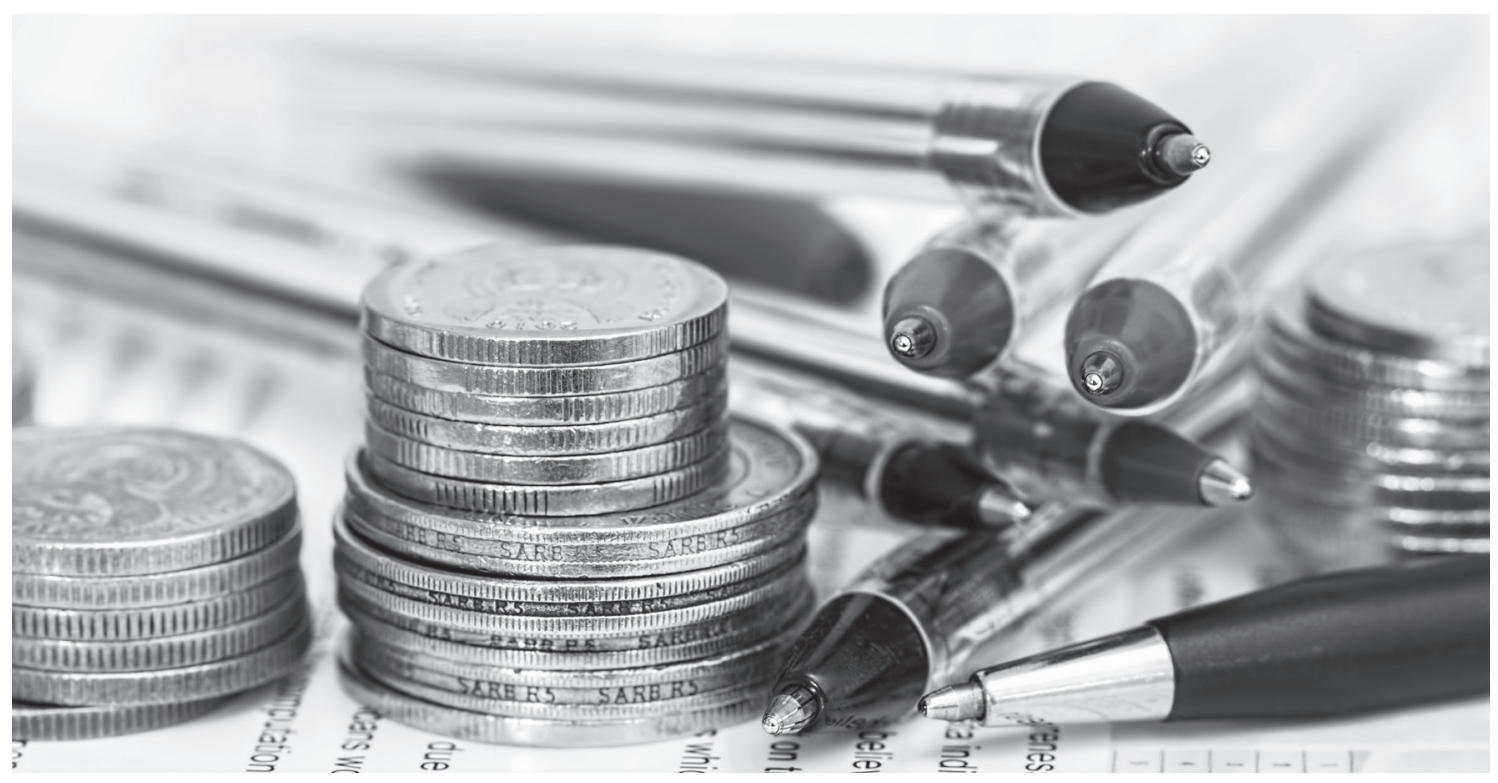

only as an attitude of the living being. Its production, therefore, presupposes its existence (Marx, 1954, p. 475).

In this short summary on the work-value question, I have chosen in a whimsical, perhaps personal way, the most obvious traces left by Professor Homero Cuevas around the enigmas of this question by the ghost of the transformation of values into prices from this accounting between working time and exchange prices. And we are dealing with this issue centrally in this issue of the Papeles Journal because...

Economic theory must be realistic, in the sense that it must be focused on the analysis of the capitalist economy in which the ownership of capital gives power, in addition to income, and where the decisions of workers, consumers and households have very important limited importance (King, 2009, p. 59).

So, the relevant core of the question, both in the sense of a theoretical construction of the problem, and in the sense of the essential question for an economic science that accounts for a more just world, is centered around the problem of values and wage prices (two fundamental questions are postponed: the fair wage and the way in which the wage can be reached fairly) ${ }^{1}$. Professor Homero Cuevas dedicated a good part of his academic life to the question of the abstract value of wages as the only coherent invariant: "All that is required for a correct determination of all prices and the rate of profit is the abstract value of wages" (Cuevas, 1984, p. 12).

The development of a theory of value in its labyrinths invites a holistic, macroeconomic view: "In terms of the theory of labor value, value added in the economy is nothing other than labor added to the means of production during the productive process" (Cuevas, 1984, p. 15). This is the reason why the best option as a measure of all goods

1 "The value of labor power is reduced to the value of a certain sum of livelihoods. It changes, therefore, by changing their value, that is, by increasing or decreasing the labor time necessary for their production" (Marx, 1954, p. 479). 
can be none other than labor. The paths of this invariant must suppose two perspectives: 1 ) labor is the only coherent invariant possible (by definition); and 2) only a global solution to the economic sectors can account for the problem between values and prices (microeconomic postulates are not always fulfilled in macroeconomic aggrega$t^{2} \mathrm{~s}^{2}$ ). A summary of the critical process on the problem of the abstract value of labor is:

Samuelson (1971) found that only when each sector of the economy satisfies the conditions of a Sraffiana standard commodity, the sum of production prices equals the sum of values and the sum of profits to the sum of capital gains obtained simultaneously. Later, Morishima (1973) demonstrated that the required condition was somewhat less restrictive: the economy, as a whole, should satisfy the conditions of a standard Sraffiana commodity, which does not imply that each individual sector must necessarily satisfy them. But in any case, as Samuelson concludes, such conditions are too distant from reality to claim that a set of propositions restricted exclusively to them can be presented as a relevant economic theory (Cuevas, 1984, p. 15).

And although...

wages fluctuate according to many diverse circumstances, such as the relative scarcity or abundance of workers in the face of capital accumulation, which makes it as inadequate as a measurement standard as the rest of ordinary merchandise, "equal amounts of labor, at all times and places, they have the same value for the worker "(Cuevas, 1986, p. 14).

The price of the amount of labor in the exchange can be masked, with previous valuations, with the privileges of initial assignments; without veil of ignorance or original position (Rawls); but the hours spent by each one of us, those hours we take away from the inescapable appointment with death, are a measure of invariable exchange as value in time, even though its price distorts the exchange of efforts, although the price transforms time in an unequal purchasing inventory.

Today, we exchange prices, faceless objects, hours without history. We live in a world of great instability in economic, moral and biological valuations; resuming the study of labor value theory could chart routes for a freer and more equitable world: a more (just) equitable one.

To conclude, as professor Homero Cuevas stated in his book The Theory of Value-Work and the Price System (1986), to close his book (paraphrase from memory): we do not know what the correct theory of value is, but we are sure that it is necessary to have a theory of value in economics, perhaps the sum of all theories. This issue of Papeles Journal invites you to reflect on the socioeconomic problems of today, in Colombia and in the world.

Enrique Ferrer-Corredor

2 The aggregate production function is a fundamental neoclassical construct. At the theoretical level, it is used in virtually every branch of economics analysis. At the empirical level, it is used to analyze the determinants of technical change and capacity utilization, and almost half a century after Solow's celebrated 1957 article, it remains the method of accounting for the determinants of growth. Yet the theoretical foundations of this construct are shaky, because it cannot be grounded in any plausible micro-foundation [...] It is curious that a tradition so insistent on the necessity of micro-foundations should rely so heavily on a construction that cannot be derived from micro-foundations (Shaikh, A., 2005, p. 447) 